\title{
Las primeras nobles y burguesas en la Real Sociedad Económica de Amigos del País de Cádiz
}

\author{
Fátima Salaverri Baro \\ Licenciada en Historia por la Facultad de Filosofía y Letras de la Universidad de Cádiz \\ e-mail: fatima.salaverribaro@cadiz.es \\ ORCID: https://orcid.org/0000-0001-7759-380X
}

\begin{abstract}
RESUMEN: En el año 1817 la Real Sociedad Económica de Amigos del País de Cádiz intentó constituir una Junta de Damas en la capital. El Archivo de la Universidad de Cádiz conserva el listado completo de las mujeres que participaron en esta iniciativa, con un valor histórico de gran interés para la Historia de las Mujeres y la Historia de España en general. El objeto de este artículo es visibilizar a estas mujeres y analizar los valores de género que ello supuso mediante el análisis de los fondos conservados en el mencionado archivo.
\end{abstract}

Palabras clave: Junta de Damas, Género, Feminismo, Filantropía.

\section{The first nobles and bourgeois of the Royal Economic Society of Friends of the Country of Cadiz.}

ABSTRACT: In the year 1817 the Royal Economic Society of Friends of the Country of Cadiz tried to constitute a Board of Ladies in the capital. The Archive of the University of Cadiz keeps a complete list of the women who participated in this initiative, of great historical value and interest for the History of Women and the History of Spain. The goal of this paper is to make these women visible and to analyse the gender values that their participation supposed through the analysis of the available archives.

Keywords: Board of Ladies, Gender, Feminism, Philanthropy.

A principios del siglo XIX la Real Sociedad Económica de Amigos del País de Cádiz intentó integrar a un grupo de mujeres en su organización para gestionar asuntos de interés social. Pretendió establecer en la ciudad una Junta de Damas al hilo de otras que ya estaban establecidas en el territorio nacional, como la Junta de Damas de Honor y Mérito de la matritense. Esta había sido fundada en el año 1787 y asumió entonces un papel relevante en la beneficencia en la capital con un encomiable trabajo centrado en la infancia abandonada en la Inclusa madrileña, en las escuelas de niñas y en la asistencia a las presas de La Galera ${ }^{1}$.

La Económica de Cádiz se creó bajo las ideas ilustradas con el objetivo de impulsar la economía de la nación. Fue un espacio donde los amigos del país consideraron que únicamente sus iguales en estatus social, es decir, damas pertenecientes a la nobleza y la alta burguesía,

\footnotetext{
${ }^{1}$ Una interpretación de los debates sobre el acceso de las mujeres a las Real Sociedad Económica de Amigos del País de Madrid puede consultarse en BOLUFER, Mujeres e Ilustración, pp. 341-371.

DOI del artículo: 
podían colaborar en este proyecto para servir de modelos a otras mujeres y contribuir, desde sus limitados papeles sociales, al bien común. Para ello pretendieron constituir en 1817 una Junta de Damas, Clase de Damas o Cuarta Clase que sería la destinada a acoger a las nuevas socias. Repitió para ello la organización interna que tenía establecida en grupos funcionales, denominados clases, formadas por la de Agricultura, la primera clase; la de Industria, la segunda y la de Comercio, la tercera. A ellas se sumaría la nueva clase.

En este escenario, y en base a la Real Orden de 24 de febrero de 1817 que recogió los esperanzadores resultados que Fernando VII esperó de la Económica gaditana, como instrumento necesario para potenciar el bien público, algunas mujeres fueron tenidas en cuenta para su desarrollo. El interés de la Sociedad gaditana por gestionar este proyecto desde una Junta de Damas siguió el modelo establecido por la corona el 9 de junio de 1815 sobre cómo se tenían que constituir las nuevas sociedades económicas surgidas tras la Guerra de la Independencia y en la que la sociedad matritense se convirtió en el modelo a seguir ${ }^{2}$. Los propios estatutos de la Económica gaditana recogieron - artículo séptimo- como «... procurará estimular a las damas a fin de que formen una quarta clase que se encargará de todos los objetos que desempeñan las Señoras de la Sociedad Económica de Madrid» ${ }^{3}$.

El 22 de mayo de 1817 se iniciaron los pasos para formar la Cuarta Clase. Presidida la entidad por Francisco Javier de Oms, marqués de Castelldosrius, empezó una profunda y dilatada colaboración entre las damas gaditanas y la Económica que, desde una perspectiva de género, permite descubrir los patrones androcéntricos que subyacían en el proyecto y que determinaron cuál fue su participación. Se recopilaron los reglamentos de los establecimientos que estaban a cargo de la Junta de Damas de Honor y Mérito de Madrid con el objeto de que, tras su estudio, se propusiese el modo de constituir la nueva Clase ${ }^{4}$. Su objeto, fundamentalmente, sería vigilar los establecimientos de beneficencia. En concreto, se trataba de que la Cuarta Clase gestionase la Casa de Expósitos de Cádiz para proteger a la infancia desvalida allí acogida que soportaba altos índices de mortalidad ${ }^{5}$. Aquellas nuevas misiones sociales estuvieron vinculadas a las labores de cuidados que ellas desempeñaban en el entorno familiar y doméstico. Supuso trasladar al ámbito público lo que la sociedad consideraba «sus especialidades domésticas». No hay que olvidar que los pilares que sostuvieron la sociedad del siglo XIX tuvieron como base el concepto de lo biológico como parte esencial de la diferencia sexual. Así, la maternidad fue lo que definió la identidad femenina y sobre ella se construyó culturalmente el discurso de género de la época. En este contexto, se usó esa maternidad social para sostener la afinidad de las mujeres con el cuidado de la infancia y se generó un discurso de la excelencia que «facultaba privilegiadamente a las mujeres para el ejercicio público de actividades íntimamente relacionadas con las asignaciones de competencia privada, que tiene reservada para su vida doméstica» ${ }^{6}$.

El inicio del nuevo proyecto estuvo vinculado a las denominadas damas electoras, es decir, un conjunto de cien mujeres ${ }^{7}$ seleccionadas y nombradas por la propia Económica y cuya misión fue elegir socias para constituir la Junta de Damas de la capital (figura 1). Desde

\footnotetext{
${ }^{2}$ Archivo de la Universidad de Cádiz (AUCA). Libro copiador de oficios y representaciones de la Sociedad Económica de Amigos del País de Cádiz, 1814-1818, L-1 SE, Oficio número 35.

3 Archivo Histórico Municipal de Cádiz (AHMCA). Estatutos de la Real Sociedad Económica Gaditana de Amigos del País, 6 de mayo de 1817, Caja 3425.

${ }^{4}$ AUCA, Libro copiador de oficios, op. cit., 1814-1818, L-1 SE, Oficio número 35.

${ }^{5}$ ESPIGADO Tocino, La Junta de Damas de Cádiz: entre la ruptura y la reproducción social, p. 244.

${ }^{6}$ Ibidem.

${ }^{7}$ El listado completo de los nombres de las cien damas electoras seleccionadas para participar en la formación de la Clase de Damas o Cuarta Clase de la Real Sociedad Económica de Amigos del País está conservado en AUCA. Libro copiador de oficios, op. cit., 1814-1818, L-1 SE, Oficio número 72.
}

DOI del artículo:

https://doi.org/10.25267/Cuad investig fondos arch UCA.2021.i3.06 
la Sociedad Económica se inició una prolija correspondencia con ellas y se les pidió que designasen cada una a veinticinco mujeres de su misma condición social - compañeras en estatus social y modo de vida-, que fueran vecinas de Cádiz y que ellas estimasen que tenían las cualidades necesarias para participar. La ternura, la humanidad, la suavidad de costumbres, todas ellas vinculadas al «bello sexo», fueron tenidas en cuenta en este proceso. Aquellas no dejaron de ser prototipos socioculturales vinculados tradicionalmente a las mujeres y que se tuvieron muy en cuenta para que ocuparan un espacio público. Pero pese a ello, fue una oportunidad para esas mujeres de posibles que ellas supieron aprovechar. Su participación como damas electoras les supuso cambiar sus modos de vida, sus implicaciones domésticas y familiares y avanzar hacia un proceso de participación pública en la filantropía de la época. Damas de gran renombre social iniciaron las tareas de detallar qué veinticinco mujeres consideraban que poseían las cualidades que solicitaba la Sociedad mientras desarrollaron un «ideal femenino abnegado y complaciente, propios de la ideología de la domesticidad tradicional» ${ }^{8}$.

Figura 1. Listado de las cien damas electoras propuestas por la Sociedad
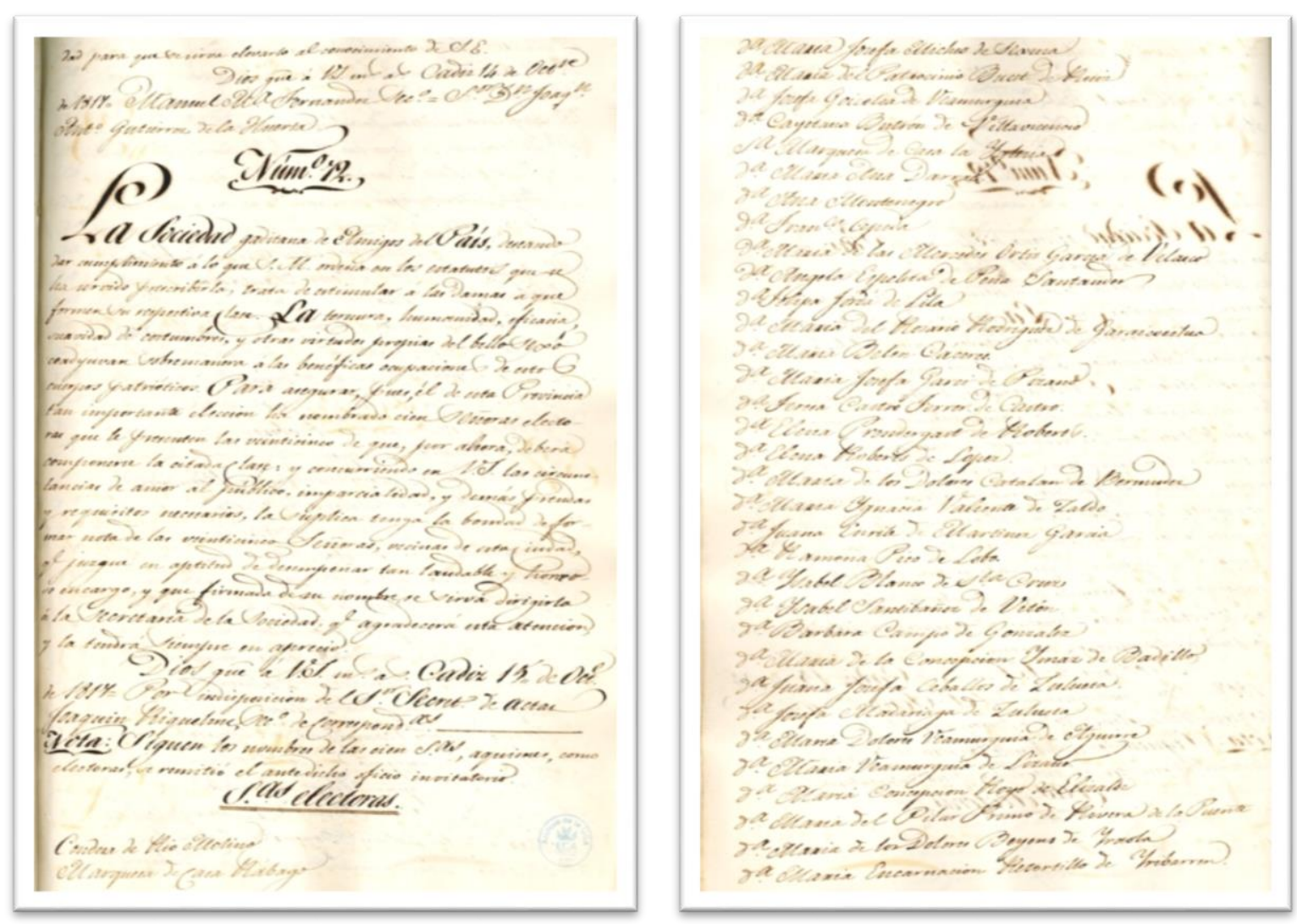

${ }^{8}$ CASTELls y otras, Activistas, conspiradoras y románticas (1823-1833), en Mujeres y cultura políticas en España 1808-1845, p. 126.

DOI del artículo: 

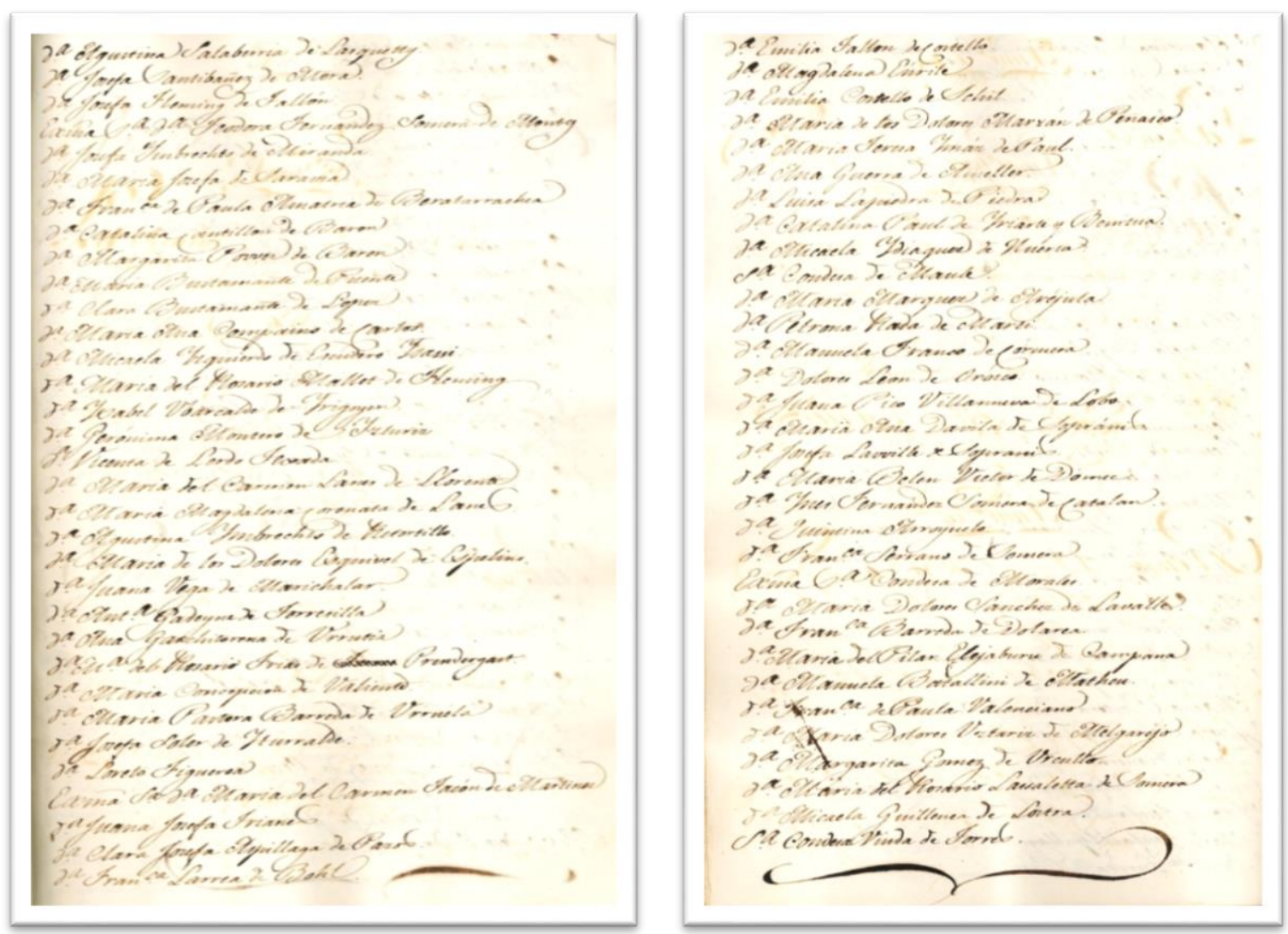

Fuente: Archivo de la Universidad de Cádiz (AUCA). Libro Copiador de oficios y representaciones de la Sociedad Económica de Amigos del País de Cádiz, 1814-1818, L-1 SE, Oficio número 72

El intento de formar una Junta de Damas permitió florecer nombres y apellidos de nobles y burguesas en una ciudad con una amplia vida social y todavía con cierta riqueza comercial. Pese a que Cádiz carecía de una potente clase aristócrata, la posibilidad de visibilizar el estatus nobiliario que residía en la ciudad fue aprovechada entonces. Las damas electoras pertenecientes a la nobleza estuvieron representadas por mujeres como Josefa Fernández de Rábago, marquesa de Casa-Rábago ${ }^{9}$, junto a su madre Mariana $\mathrm{O}^{\prime}$ Rian, marquesa viuda de Casa-Rábago.

Josefa Fernández de Rábago llegó a ser una de las mujeres más influyentes de la ciudad cuando se constituyó la Junta de Damas, de manera definitiva, el 8 de marzo de 1827. Aprendió de su madre la gestión de una asociación al haber visto sus formas y maneras de trabajar como vicepresidenta de la Junta Patriótica de Señoras de Fernando VII ${ }^{10}$ en Cádiz durante la Guerra de la Independencia, junto a su presidenta, María Tomasa Palafox y Portocarrero, marquesa de Villafranca. Tras el fallecimiento de su padre, Francisco Fernández de Rábago, marqués de Casa Rábago, Josefa Fernández de Rábago heredó la titularidad del marquesado ${ }^{11}$. Nacida en

\footnotetext{
${ }^{9}$ AUCA. Libro copiador de oficios, op. cit., 1814-1818, L-1 SE, Oficio número 72.

${ }^{10}$ La Junta de Señoras de Fernando VII fue una organización civil de mujeres formada por damas de alta posición social que, desde 1811 en el Cádiz asediado por las tropas francesas durante la Guerra de la Independencia, estuvieron en activo con el visto bueno del Consejo de Regencia. Su presidenta fue la marquesa de Villafranca, Tomasa de Palafox. Esta Junta fernandina que recaudó más de un millón de reales, facilitó vestimentas al ejército y ayudó en los hospitales de campaña, contribuyó a la independencia del país.

${ }^{11}$ Archivo Histórico Provincial de Cádiz (AHPCA). Poder para testar entre D. Francisco Fernández de Rábago y Dña. María Ana O’Rian, 17 de abril de 1817, Protocolos Notariales, L. 1877, fol. 619.
}

DOI del artículo: 
Cádiz el 19 de octubre de $1775^{12}$ fue llamada a ser una de las figuras más importantes de la historia de la Junta de Damas de la Sociedad Económica de Amigos del País de Cádiz donde desempeñó una larga carrera al frente de la misma hasta su fallecimiento el 30 de julio de $1861^{13}$. Pertenecer a la Junta de Damas supuso para Josefa Fernández de Rábago volver a participar en una agrupación cívica de señoras tras su experiencia como socia de la Junta Patriótica fernandina.

Otras damas pertenecientes a la nobleza ejercieron su labor aquellos días en calidad de damas electoras, como María Joaquina Jiménez de Velasco y Boneo, condesa de Maule; María Encarnación de Clemente Palacios, condesa de Río Molino; Joaquina Laiglesia, marquesa de Casa Laiglesia o Josefa Álvarez y Mancilla, condesa viuda de Morales de los Ríos.

La condición nobiliaria de las damas también quedó acreditada por la pertenencia a familias que ostentaban cargos honoríficos en alguna orden militar. Fue el caso de damas electoras como María Belén Casares y Mendoza, casada con Manuel Rodríguez de Alburquerque, caballero de la corporación nobiliaria de la Real Maestranza de la Caballería de Ronda ${ }^{14}$ o María Mercedes Ortiz de Artacho, casada con Francisco Javier García de Velasco, caballero de la Orden de Carlos III, de la Real y Militar Orden Constantiniana de San Jorge y maestrante de la Real Maestranza de la Caballería de Ronda ${ }^{15}$. La propia marquesa de Casa Rábago estaba casada con Antonio Artecona ${ }^{16}$, caballero de la Orden de Santiago y de la Real y Militar Orden de San Hermenegildo ${ }^{17}$.

Las mujeres de las élites también representaron a familias vinculadas tradicionalmente al comercio, en una ciudad que intentaba recuperarse de la Guerra de la Independencia y observaba los movimientos emancipatorios de las colonias americanas ${ }^{18}$. En los círculos mercantiles gaditanos hubo una mentalidad favorable a que las mujeres recibieran nociones sobre los negocios para que no quedasen desasistidos ante ausencias de padres y maridos ${ }^{19}$. Por ello, las burguesas gaditanas, en ocasiones, se incorporaron a la actividad familiar cuando sus esposos se encontraban ausentes en viajes comerciales y cuando fallecían se hacían cargo del negocio. En este contexto surgen nombres entre las damas electoras como Manuela Batellín Copas, que en el año 1817 era ya viuda del comercial Miguel Matheu y poseía la casa de Comercio Viuda de Miguel Matheu e Hijos que, como otras viudas, pero también en algunos casos mujeres casadas y solteras, participaron con una estrategia propia en el mundo

\footnotetext{
${ }^{12}$ Archivo General Militar de Segovia (AGMS). Certificado de Bautismo de Dña. Josefa Fernández de Rábago O’Rian, 17 de septiembre de 1795, en Expediente matrimonial de D. Antonio Artecona Salazar Rodríguez de Picón, Leg. A 2552, 1795.

${ }^{13}$ Otras mujeres en otros años y en otras ciudades también desarrollaron una ardua labor al frente de las juntas de damas. Recordar a María Lorenza de los Ríos y Loyo, marquesa de Fuerte Híjar, que ejerció como presidenta de la Junta de Damas de Honor y Mérito de la Sociedad Económica de Amigos del País de Madrid desde el 11 de noviembre de 1811. Fue admitida como socia en agosto de 1788 y tuvo una enorme participación en diferentes labores sociales, culturales y benéficas. Cabe mencionar sus actividades para el Asilo de Criadas, el Montepío de Hilazas y varias obras filantrópicas a menudo en colaboración con María Francisca Sales de Portocarrero, condesa de Montijo. ACEREDA, La Marquesa de Fuerte-Híjar. Una dramaturga de la Ilustración. Estudio y Edición de la Sabía Indiscreta, p. 196.

${ }^{14}$ AHPCA. Testamento de Dña. María Belén Casares Mendoza, 30 de octubre de 1799, Protocolos Notariales, L. 1206, fols. 305-310.

${ }^{15}$ AHPCA. Testamento de Dña. Mercedes Ortiz Artacho, 28 de septiembre de 1859, Protocolos Notariales, L. 3287, fols. 1180-1194.

${ }^{16}$ Archivo Parroquial Iglesia Nuestra Señora del Rosario de Cádiz. Libro de Matrimonios número 1, fol. 123.

${ }^{17}$ AGMS. Expediente matrimonial de D. Antonio Artecona Salazar Rodríguez de Picón, Leg. A 2552, 1795.

${ }^{18}$ RAMOS SANTANA, Cádiz en el siglo XIX, p. 93.

19 JAFFE y MARTÍN-VALDEPEÑAS YAGÜE, Sociabilidad, filantropía y escritura: María Lorenza de los Ríos y Loyo, marquesa de Fuerte-Hijar (1761-1821), en Mujeres y culturas políticas en España 1808-1845, p. 85.
}

DOI del artículo:

https://doi.org/10.25267/Cuad investig fondos arch UCA.2021.i3.06 
de los negocios ${ }^{20}$. Lo mismo sucedió con otra dama electora, Elena Prendergast Sweetman, viuda del comerciante Mauricio Roberts y que mantuvo la casa de comercio local bajo el nombre de Viuda de Roberts y Compañía.

La ciudad de Cádiz era diferente al resto de ciudades de España pues «por la gran concurrencia de extranjeros y la diversidad de origen entre sus habitantes se asemejaba a otras poblaciones europeas ${ }^{21}$. No todas estas mujeres representantes del poder local ante la Económica nacieron en Cádiz. En el siglo XVIII un porcentaje próximo al cincuenta por ciento de la población procedía de distintas áreas geográficas «lo que permitió que el colectivo mercantil cosmopolita de Cádiz procediese de familias con origen en Andalucía occidental, Navarra, País Vasco, Cataluña, Francia, Irlanda e Italia» ${ }^{22}$. Las señoras electoras de 1817 representaron a muchas de aquellas familias venidas de fuera. Como Antonia O’Crouley Power que, aunque había nacido en Cádiz, tanto su madre, María Dolores Power Gil como su padre, Pedro Alonso O’Crowley tenían raíces irlandesas. De la misma manera, Elena Prendergast procedía de Irlanda. Junto a ellas, otras damas como María Concepción Iraola, Clara Josefa Azpillaga o Ana Izalbaceta de García eran de origen vasco-navarro. Actuaron entonces como damas electoras, pero desde 1827 fueron socias de la Junta de Damas y defendieron los intereses gaditanos en los que trabajaron desde la escuela de niñas pobres o en el cuidado de la población expósita. Junto a ellas, otras damas de posibles eran miembros de familias sin tradición marinera y que, sin embargo, acudieron masivamente al Cádiz comercial desde finales del siglo XVII. Típicamente navarro fue un importante apellido en los círculos mercantiles de la época y que posteriormente tuvo renombre en la política como los Istúriz, a cuya familia estaba vinculada la electora Jerónima Montero, viuda de Tomás Istúriz.

Dentro del amplio abanico de electoras de la burguesía las había también que tenían lazos familiares con hombres de negocios procedentes de las colonias americanas o ellas mismas tenían allí sus orígenes. María Ana Compains y Alegría, nacida en Santa Fe y Real de Minas de Guanajato (México), estaba casada con Juan Miguel de Carlos, vinculado al comercio de la Carrera de Indias y cónsul del Real Tribunal del Consulado de Cádiz. La socia electora María Mercedes Caballero La Mota era de Puerto Príncipe (Haití); María Ignacia Valiente de Zaldo, secretaria de la futura Junta de Damas de Cádiz desde el año 1827, procedía de México (reino de Nueva España). Asimismo, Margarita Gómez Carriles de Urcullu, que ejerció de comisaria del barrio del Pilar como socia de la Junta Patriótica de Señoras de Fernando VII, era natural de la villa colombiana de Honda (Santa Fe); Francisca Cepeda Mayo ${ }^{23}$ disfrutó de réditos correspondientes de propiedades en Montevideo y Santa Fe de Bogotá, gestionadas a través de su apoderado de Cartagena de Indias. María Encarnación Clemente de Francia, condesa de Río Molino, nació en la ciudad de Pariana en la provincia de Caracas (Venezuela) en el Virreinato de Nueva España. Junto a ellas, en esta ciudad cosmopolita otra socia como Elena Prendergast procedía de Cork (Irlanda) dado que «los pingües beneficios del comercio con las Indias permitieron que a finales del siglo dieciocho hubiese en la ciudad unas treinta casas de comercio inglesas, unos cien armadores o propietarios de buques $\gg^{24}$.

\footnotetext{
${ }^{20}$ FERNÁNDEZ PÉREZ, El rostro familiar de la metrópolis: redes de parentesco y lazos mercantiles en Cádiz, 1700-1812, p. 11.

${ }^{21}$ RAMOS SANTANA, op. cit., p. 62.

${ }^{22}$ FERNÁNDEZ PÉREZ, op. cit., p. 258.

${ }^{23}$ Francisca Cepeda fue hermana de Rosario Cepeda que también fue socia de la Junta de Damas de Madrid desde sus inicios y desempeñó el cargo de secretaria entre 1807 y 1813 . Llegó a ser Regidora Honoraria de la ciudad de Cádiz. AZCÁRATE Y RISTORI, Una niña Regidora Honoraria de la ciudad de Cádiz.

${ }^{24}$ COMEllas García-LlerA, Dinámica y mentalidad de la burguesía gaditana en el siglo XVIII en La Burguesía Mercantil Gaditana (1650-1868), pp. 20-21.
}

DOI del artículo:

https://doi.org/10.25267/Cuad investig fondos arch UCA.2021.i3.06 
Algunas señoras estuvieron vinculadas al ámbito $\operatorname{militar}^{25}$ y por ello fueron reclamadas por la Sociedad Económica. Cayetana Butrón, casada con Rafael Villavicencio, jefe de escuadra de la Armada Nacional ${ }^{26}$; Adelaida Pareja Septien, era hija de Antonio Pareja teniente general del ejército y como se ha mencionado caballero de la Orden de Santiago; Agustina Salaverria fue viuda del coronel Francisco de Alburquerque; Francisca Cepeda, viuda de Tomás de Ugarte, jefe de escuadra de la Armada Nacional ${ }^{27}$ o la propia María Loreto Figueroa y Montalvo ${ }^{28}$, viuda del Capitán de Navío de la Armada Nacional, Ramón Carasa ${ }^{29}$, entre otras.

Otras mujeres de posibles que fueron llamadas por la Económica también estaban relacionadas con otros sectores con poder social de la ciudad. En el ámbito de las sociedades económicas de amigos del país «se unieron con un mismo objetivo la aristocracia de grandes títulos y posesiones, al lado de funcionarios, militares y profesionales y componentes del clero ${ }^{30}$. Ángela Ezpeleta y Pocy estaba casada con Joaquín de la Peña y Santander, oidor honorario de la Real Audiencia de Sevilla y asesor general de rentas y alzadas en la ciudad, o Luisa Francisca de la Piedra, con el primer cónsul del Real Tribunal del Consulado de Cádiz. Asimismo, el ámbito eclesiástico también estaba representado entre las damas electoras a través de Juana Josefa Trianes Rivero, hermana del canónigo de la Catedral de Cádiz, Antonio Manuel Trianes.

La presencia de las damas electoras en este proyecto también estuvo vinculada a socios de la Económica. Ana Rodríguez Guerra, casada con el socio Carlos Francisco Ameller. La dama electora Ana Montenegro con el socio José María Gutiérrez de la Huerta; Juana Ceballos con Pedro Juan de Zulueta; María Manuela Bustamante con Pedro de la Puente o Rafaela Buseti con Santiago José de Terry socio de número de la Económica, entre otras.

Para aquellas mujeres de posibles no les fue extraño participar en una organización como la que en aquellos momentos les reclamaba. Muchas fueron socias y habían participado activamente en la Junta Patriótica de Señoras de Fernando VII fisurando, en cierta medida, el orden social marcado para ellas. Su experiencia en la Guerra de la Independencia les permitió un cuestionamiento de sus papeles en la sociedad y los roles de género vigentes. El haber sido nombradas damas electoras por la Sociedad Económica de Amigos del País supuso para este grupo de cerca de cien mujeres pasar a una posición social pública que les permitió acceder a cierto poder social. Ellas se sirvieron de la maternidad, que era un rasgo definitorio de la identidad femenina, para realizar una función social pública alejadas de las paredes privadas del hogar. Junto a los lazos de pertenencia a una misma clase social entre las damas electoras había asimismo lazos familiares. Josefa Fernández, marquesa de Casa Rábago, era hija, como se ha mencionado, de Mariana O`Rian, marquesa viuda de Casa Rábago. Josefa Goycolea de

\footnotetext{
${ }^{25}$ De manera similar a las damas electoras gaditanas cabe destacar que, mayoritariamente, las damas de la Orden de María Luisa creada en 1792 estaban casadas con hombres que ostentaban dignidades de las órdenes militares, de la de Carlos III o del Toisón de Oro, otros fueron oficiales generales, tenientes generales e incluso algunos capitanes generales. Molas RiBALTA, Las primeras damas de la Orden de María Luisa, p. 275.

${ }^{26}$ AHPCA. Testamento de Dña. Butrón de Villavicencio, 20 de diciembre de 1844, Protocolos Notariales, L-M. 185, fols. 684-686.

${ }^{27}$ AHPCA. Testamento de Dña. Agustina Salaverria Sánchez de Madrid, 6 de noviembre de 1833, Protocolos Notariales, L. 476, fols. 1041-1042.

${ }^{28}$ María Loreto Figueroa y Montalvo había nacido en Cádiz y «después de años de residencia en Madrid, había regresado a Cádiz tras haber colaborado activamente en la Sociedad de damas madrileña, aquí residió hasta su muerte». EsPigAdo Tocino, 2009, p. 332. Ejerció el cargo de secretaria de la Junta Patriótica de Señoras de Fernando VII.

${ }^{29}$ AHPCA. Testamento de Dña. María Loreto Figueroa y Montalvo, 31 de enero de 1822, Protocolos Notariales, L. 3189, fols. 82-88.

${ }^{30}$ Molas RiBAlta, op. cit., p. 4.

DOI del artículo:

https://doi.org/10.25267/Cuad investig fondos arch UCA.2021.i3.06 
Veamurguía era hija de la dama electora, María Josefa de Veamurguía de Goycolea. Y, asimismo, la electora Teresa Laborde llegaría a incorporar años después a su hija Isidra Carrera que llegó a ser presidenta de la Junta de Damas en los años sesenta tras el fallecimiento de Josefa Fernández de Rábago. Ello les facilitó generar redes de apoyo entre ellas y fomentar un sentimiento de identidad y pertenencia en los nuevos designios filantrópicos para los que eran reclamadas.

Los trabajos para formar la nueva clase finalizaron a finales de enero de 1818. Del total de damas propuestas treinta y cinco nobles y burguesas recibieron un mayor número de votos. La dama más votada con setenta y tres votos resultó ser Josefa Santibáñez de Mora que había desempeñado ya trabajos en la filantropía como socia de la Junta Patriótica de Señoras de Fernando VII.

Pese a todos los trabajos iniciados el proyecto de constitución de una Junta de Damas no logró ver sus frutos. Las damas más votadas fueron consideradas como socias ya nombradas, aunque la propia Sociedad reconocía que no estaba en funcionamiento porque carecía de contenidos para ellas al no tener la Sociedad Económica de Amigos del País de Cádiz autorización real para acceder al cuidado de la población infantil acogida en la Casa de Expósitos. El proyecto de constitución de la nueva Clase fue un asunto pendiente que se dilató durante varios años. La propia Sociedad Económica fue consciente de ello. En el año $1825^{31}$, sabedores los amigos del país que el proyecto de gestión de la Casa de Expósitos era más complicado de los que ellos mismos habían supuesto, abrieron el camino para vincular su Junta de Damas al establecimiento de una escuela gratuita de niñas pobres. Hubo que esperar dos años, en 1827, para que la Junta de Damas de Cádiz iniciase su irrupción en la historia permitiendo una gradual evolución, a veces con retrocesos, hacia nuevas formas de participación de estas mujeres en la sociedad.

\section{REFERENCIAS BIBLIOGRÁFICAS}

ACEREDA, A. La Marquesa de Fuerte-Híjar. Una dramaturga de la Ilustración. Estudio y Edición de la Sabía Indiscreta. Cádiz: Servicio de Publicaciones, Universidad de Cádiz, 2000. ISBN: 84-7786-662-7.

AzCÁRATE Ristori, I. Una niña Regidora Honoraria de la ciudad de Cádiz. Cádiz: Quorum Libros Ediciones, 2000. ISBN: 84-88599-35-8.

BOLUFER, M. Mujeres e Ilustración. La construcción de la feminidad en la España del siglo XVIII. Valencia: Diputación de Valencia, 1998. ISBN: 84-7822-237-5.

CASTElls, I., et al. Activistas, conspiradoras y románticas (1823-1833). En: YeTANO LAGUNA, Ana (coord.). Mujeres y cultura políticas en España 1808-1845. Barcelona: Servicio de Publicaciones, Universidad Autónoma de Barcelona, 2013. pp. 127-160. ISBN: 978-84-490-3346-9.

COMEllas García-Llera, J. L. Dinámica y mentalidad de la burguesía gaditana en el siglo XVIII. En: La Burguesía Mercantil Gaditana (1650-1868). Cádiz: Instituto de Estudios Gaditanos, Diputación Provincial de Cádiz, 1976, pp. 13-40. ISBN: 84-85268-01-6.

EsPigado Tocino, G. La Junta de Damas de Cádiz: entre la ruptura y la reproducción social. En: Espigado Tocino, Gloria y PAScuA SÁnchez, María José de la (eds.). Frasquita Larrea y Aherán. Europeas y españolas entre la Ilustración y el Romanticismo (1750-

${ }^{31}$ Guía General de Forasteros en Cádiz para el presente año de 1825, Cádiz, Imprenta de Don José Niel, 1825, pp. 58-59.

DOI del artículo:

https://doi.org/10.25267/Cuad investig fondos arch UCA.2021.i3.06 
1850). Cádiz: Universidad de Cádiz-Ayuntamiento de El Puerto de Santa María, 2003, pp. 243-266. ISBN: 84-7786-852-2.

EsPigado Tocino, G. La marquesa de Villafranca y la Junta de Damas de Fernando VII. En: Castells Oliván, Irene, Espigado Tocino, Gloria y Romeo Mateo, María Cruz (coords.). Heroínas y Patriotas: Mujeres de 1808. Madrid: Cátedra, 2009, pp. 317-342. ISBN: 978-84-376-2575-1.

FERNÁNDEZ PÉREZ, P. El rostro familiar de la metrópolis: redes de parentesco y lazos mercantiles en Cádiz, 1700-1812. Madrid: Siglo XXI, 1997. ISBN: 84-323-0961-3.

Guía General de Forasteros en Cádiz para el presente año de 1825. Cádiz: Imprenta de Don José Niel, 1825, pp. 58-59.

JAFFe, C. y MARTíN-VALDEPEÑAs YagÜE, E., Sociabilidad, filantropía y escritura: María Lorenza de los Ríos y Loyo, marquesa de Fuerte-Hijar (1761-1821). En: YetanO LAGUNA, Ana (coord.). Mujeres y culturas políticas en España 1808-1845. Barcelona: Servicio de Publicaciones, Universidad Autónoma de Barcelona, 2013, pp. 83-124. ISBN: 978-84-490-3346-9.

Molas Ribalta, P. Las primeras damas de la Orden de María Luisa. En: Trocadero [en línea]. Cádiz, Servicio Publicaciones de la Universidad de Cádiz. [Consulta: 6 de octubre de 2020]. Disponible en: DOI http://dx.doi.org/10.25267/Trocadero.2001.i12.12

Ramos SANTANA, A. Cádiz en el siglo XIX. De ciudad soberana a capital de provincia. Cádiz: Sílex, 1992, vol. III. ISBN: 84-7737-040-0. 